\title{
Regional Competition and Sustainable Development of Tourism Industry in the Synthesis of Game Theory
}

\author{
Jiajia Xu ${ }^{1 * *}$, Huawen Shen ${ }^{2}$

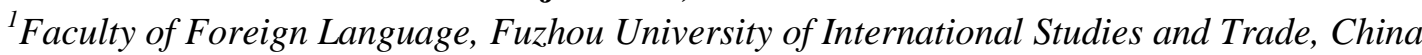 \\ ${ }^{2}$ Faculty of International Tourism and Management, City University of Macau, China \\ *corresponding author
}

\begin{abstract}
It is the premise and effective means to realize the sustainable development of rural tourism industry to understand and analyze the connotation of rural tourism correctly and to plan rural tourism reasonably. Grounded on the theoretical synthesis of rural tourism development and planning at home and abroad, this study combined game theory to analyze the environmental protection problems in rural tourism development as well as planning, the interest behavior and development among the core stakeholders of tourism community, to provide valuable guidance for rural tourism development and planning in Fujian Province.
\end{abstract}

Keywords: rural tourism industry, game theory, protection and development, stakeholders, dynamic cooperation

\section{Introduction}

As an irreplaceable tourism product, rural tourism has become an important way to experience rural culture and rural heritage. Its well-projected development can realize economic, social and environmental benefits for boosting rural tourism, serving as a new impetus for rural economic construction [8]. However, since the market dominates our country's rural tourism, most rural tourism products develop without planning or reasonable schedule, leading to the unsustainable outcome and developing imbalance in rural community, economy, and environment [8]. Therefore, a correct fathom and analysis of the connotation of rural tourism and a reasonable planning are the prerequisites and effective means to realize the sustainable development of rural tourism destinations [9]. Based on the theoretical analysis of rural tourism development both home and abroad, game theory is used in this research-to-research environmental protection issues in rural tourism development, and the interest behavior and development of core stakeholders in the tourism community in order to provide valuable guidance for the development and planning of rural tourism in Fujian Province.

This paper applies the basic principles of game theory to analyze and understand the contradictions between rural tourism development and the environmental protection of surrounding areas, establish a game model to analyze the benefits of each game party, and seek effective decisions to deal with environmental protection issues in rural tourism development. Secondly, game theory and analytical methods will be used to analyze the game behaviors of the government, tourism companies, tourists and other core stakeholders in pursuit of their own interests and the relationship pattern formed based on them. On the basis of non-cooperative game analysis, this article will explore the possibilities and methods of dynamic cooperation between its core stakeholders; by using model assumptions, the cooperative game will be scrutinized in terms of the relationship between government and tourism enterprise clusters, as well as the three main tourism stakeholders of the government and tourism enterprises. Finally, taking the construction of Manchu style scenic spot in Qinjiang Village in the development of rural tourism in Changle City, Fujian Province as an example, this paper makes an empirical study on the theory studied.

Based on the game theory in economic theory, this paper combines qualitative and quantitative research, theoretical analysis and empirical analysis to analyze the coordination of rural tourism development and protection, the conflict of interest of the core stakeholders involved in the process of development planning.

ISSN: 0010-8189

(C) CONVERTER 2020 


\section{Literature Review}

The rise of rural tourism abroad can be traced back to Britain in the middle and late 19th century: fast-paced lifestyle, serious pollution of industrial cities, so that a large number of urban residents to leisure into the countryside; at the same time, the development of railway and other transportation facilities, greatly improved rural accessibility, but also for the modern people's Congress scale into the countryside, visit the countryside to create conditions [11].

\subsection{Concept of Rural Tourism}

Foreign countries have a in-depth study of the concept of rural tourism. Inskeep [10] think that the references of agricultural tourism, farm tourism, rural tourism can be replaced by each other and need not be distinguished, and the traditional culture and folk culture tourism in remote villages should be distinguished when called Village tourism.

Lane [11] put forward five elements to define rural tourism: (1) Location of rural areas; (2) Broad natural environment and traditional cultural activities; (3) Small-scale enterprises; (4) Traditional characteristics of society and culture; (5) Tourism types are diverse. The relationship between rural tourism, agricultural tourism, and farm tourism considers that agricultural tourism and farm tourism are the largest and most unique branches of rural tourism.

The European Union (EU) and the Organization for World Economic Cooperation and Development (OECD,1994) define this kind of travel as rural tourism, in which "Rurality is the most important symbol to define rural tourism. Many scholars have recognized this view.

\subsection{Influence of Rural Tourism on Rural Economy and Social Development}

Scholars generally believe that rural tourism is conducive to rural economic development and economic transformation. For example, Slee [17] survey of rural tourism in Scotland shows that rural tourism plays an important role in promoting local economic development.

Tribe [18] think that the development of rural tourism and the protection of rural cultural traditions are contradictory to some extent, and their development strategies should be paid attention to. A study by Forsyth [6] of a small mountain village in northern Thailand shows that tourism divides rural societies, and that increasing land use intensity can lead to environmental degradation.

\subsection{Basic Theory of Rural Tourism Planning}

The basic theories of rural tourism planning mainly include destination life cycle and landscape ecology theory.

2.3.1 Destination life cycle

Life cycle appears in each destination. As proposed by Butler [2] in Tourism Area Life Cycle (TALC) model and adapted by Miller and Gallucci [15], it looks like the figure 1 below. 


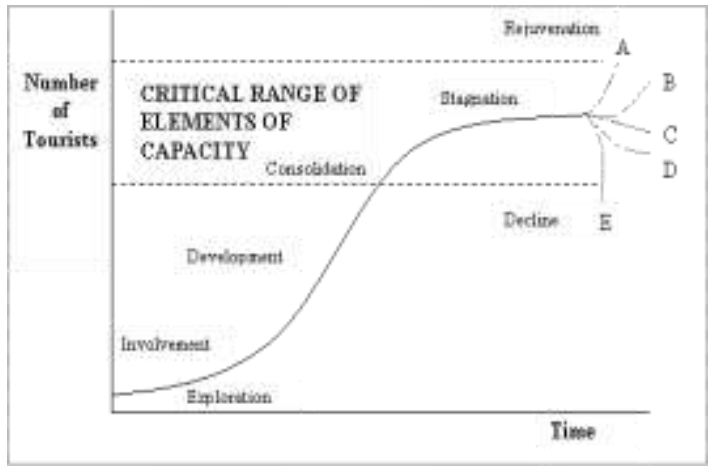

Fig 1 Tourism Area Life Cycle (TALC)

Exploration: The destination is regarded as a relatively unknown place to visitors. Voyagers at first come in little numbers that are limited by access, offices, and nearby information.

Development: With word spreading about the destination, there is an improvement in attractions and more tourists that come to the area.

Stagnation: A set carrying capacity is achieved, which is determined by social and environmental restrictions.

Rejuvenation towards A\&B: As technology and infrastructure increases, the carrying capacity is getting improved and more travelers can come.

Decline towards C\&D: That destination becomes more congested and unsustainable attracts less visitors or tourists to a place that is always overcrowded.

Decline towards E: This is usually the aftermath of a disaster, both natural and manmade [4].

In rural tourism planning, we should have a full understanding of the complexity of the factors that affect the evolution of tourist destinations or tourism products, grasp the main factors in different stages of development, and pay attention to the external conditions and the influence of competitive objects while considering the internal causes of tourist destinations with an aim to promote the tourist area to maintain gravity, prolong its development stability and prevent the arrival of debilitating period.

\subsubsection{Landscape Ecology}

Landscape ecology is the research placing more consideration on the pattern and interaction between ecosystems within a region of interest and how the interactions affect ecological processes, especially the unique effects of spatial heterogeneity on these interactions [19]. The principle of landscape ecology includes the principle of overall optimization and combination, diversity, individuality, and principle of protection of legacy land. Rural tourism planning should be guided by those principles [7].

In rural tourism planning, under the guidance of the principles of landscape ecology, that is, the principle of overall optimization and combination, the principle of diversity, the principle of individuality and particularity, the principle of protection of legacy land and the principle of comprehensive benefit, the functions of the three levels of rural landscape resources providing the first production of agricultural products, protecting and maintaining the ecological environment, and serving as a special tourism and sightseeing resource should be reflected [12].

\subsection{Game theory}

The creation of game theory was marked by the famous book Game Theory and Economic Behavior, written by Von Neumann and Morganston [22]. This landmark masterpiece proposed two basic frameworks of game theory: non-cooperative game and cooperative game. Since then, game theory has developed rapidly, almost guiding the research in most fields. In the 1970s, game theory became one of the main methods 1970s. In the 1990s, Professor

ISSN: 0010-8189

(C) CONVERTER 2020 
Zhang Weiying introduced game theory to China, and game theory research in China has made great progress. The gaps in tourism literature are twofold. One gap is a competition model for the overexploitation of resources in commons among the tourism industry. Feeny, Hanna,and McEvoy [5] elucidate that the tragedy of the commons is not complete such that it needs "a richer and more accurate framework" (p. 187). Vail and Hultkrantz [21] question in the "helpful game" that lessens clashes among land uses and advantages the two proprietors and vacationers. Game hypothesis ought to be accommodating to tackle the contentions. Williams (2001) reports that a steady environment couldn't be suitable for touristic settings and recommend a social Western way to deal with control wellsprings of undesired change. In this methodology, collaboration and struggle are concentrated in a game hypothesis; either strategy needs are moved from horticultural creation to sporting admittance to the open country or free is decreased to nature settings. Something else, customizing the worth of a scene will escalate clashes over how regular scenes ought to be created and overseen. The other hole is the utilization of time arrangement in serious vacationer locations. Buhalis [3], Uysal, Chen, and Williams [20], Milhalic [13], Kozak [10], and Ritchie and Crouch [16] report that legislatures submit significant endeavors and assets to upgrade their objections' pictures and appeal levels.

Game theory is used in many fields. In the fields of politics and military science, game theory is used to analyze important issues such as election strategy, competition problem, cause of war, legislative agenda arrangement and so on. Game theory has been the most successful part of economic theory in the past 20 or 30 years. Game theory has become a method of the whole social science [14]. Game theory provides a systematic way for people to formulate strategies when their fate depends on the behavior of others [1]. Especially when many interdependent factors coexist and no decision can be independent of many other decisions, game theory can reflect great value. In the development of tourism, game theory can explain the root causes of many inefficient phenomena in the tourism economy, find out the institutional reasons leading to inefficiency, and help the government formulate, modify policies, perfect the trading system, and improve economic efficiency [14]. The problem of credibility and repeated game in dynamic game theory reveals the long-term stability of tourism economic environment and economic order and plays a very important role in improving economic efficiency [25]. That is to say, when the government formulates the tourism policy, it tries to maintain the long-term stability of the policy, as well as the long-term behavior which is beneficial to the cultivation of enterprises and other economic organizations, which is very important to improve the social and economic efficiency. This has a great guiding role in the formulation of government tourism-related economic policies [24].

\section{Methodology}

The growing trend of rural tourism will affect the natural ecological environment around its tourist destination. The game equilibrium theory is used to analyze game behavior of stakeholders in the development of rural tourism resources development projects. It is helpful to the stability of rural tourism development revenues and ensure the sustainable development of rural tourism activities. The application of game theory in environmental protection is to quantify the results of decision-making behavior between enterprises and governments involved in environmental protection and to express the relationship between each other more intuitively.

\subsection{Game of Development and Protection between Tourism Enterprises}

Environmental pollution should be prevented and protected at the same time, but because of the external economy, enterprises in the unconstrained environment to maximize profits, would rather pollute the environment than install expensive pollution treatment equipment. Therefore, under the condition of complete market without government organization, it often leads to the environmental problems of tourism development. In this market environment, the payment and income of environmental protection by all parties to the enterprise affect each other, not only to consider their own payment and income to environmental protection, but also to ponder the other party's payment and income behavior in the development and protection of tourism resources.

3.1.1 Model assumptions

In this game, because the nature of tourism enterprises is to produce tourism products and obtain sales benefits,

ISSN: 0010-8189

C CONVERTER 2020

www.converter-magazine.info 
enterprises generally have a complete understanding of the profits of enterprises with the same scale or producing the same products. Therefore, the game is a complete information static game. The following assumptions can be made:

\section{a. Players}

To have two tourism enterprises of general scale A, B, and the two sides of the game are rational, fully understand each other's information, and choose their own decisions independently at the same time.

\section{b. Strategies}

Assuming that tourism enterprises A, B in the development of tourism, there are two options for polluted environmental resources: investment protection and non-protection. And both sides in the decision-making, the other side of the decision-making behavior information are fully understood.

\section{c. Payoff of players}

The profit of enterprises A protecting the polluted environment when producing tourism products is set up as R1, while the profit of enterprises B protecting the polluted environment when producing tourism products is set up as $\mathrm{R} 2$; The profit of enterprises not investing in the polluted environment when producing tourism products is set up as $\mathrm{N} 1$, while the profit of enterprises not investing in the protected environment when producing tourism products is set up as $\mathrm{N} 2$. The above-mentioned environmental protection game model between enterprises can be represented by the following matrix Fig 2:

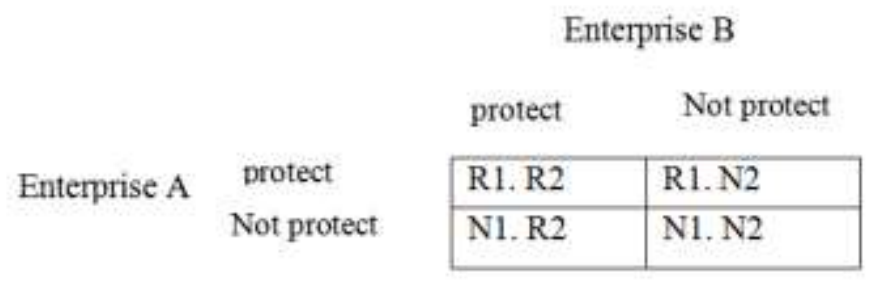

Fig 2 Profit matrix between enterprises

\subsubsection{Model analysis (Fig 2)}

The profit matrix between the two enterprises is shown in Fig 2, in which the first number is the benefit of Enterprise A and the second number is the benefit of Enterprise B. Table 1. There is a betterment in environmental protection, but because of the long-term nature of environmental improvement, investment in environmental protection is often greater than the immediate benefits of the short-term, that is, N1>R1, N2>R2. Obviously, no matter what kind of decision the enterprise A choose, the optimal decision of the enterprise B is not protected (benefit is N2); conversely, whether the enterprise chooses protection or not, the dominant strategy of the enterprise A is also not protected (benefit is N1). To sum up, the Nash equilibrium between enterprise A and enterprise B is (not protected, not protected), which is the "prisoner's dilemma" between enterprises, and the phenomenon of "commons tragedy" in environmental problems at the same time.

The reason for this phenomenon is that enterprises only consider external economic interests. As a rational economic person, enterprises $\mathrm{A}$ and $\mathrm{B}$, from their own interests, often choose the strategy of not protecting the environment to maximize profits, that is, rather pollute the environment than pay expensive governance costs, such continuous development behavior often leads to market failure. If an enterprise invests in environmental protection for altruism, but other enterprises still pollute the environment, the production cost of the enterprise will also increase accordingly, thus losing competitiveness in the market of the same products, and leading to low efficiency, or even bankruptcy. It is precisely because of this mode of tourism production that enterprises are driven not to increase profits through more effective use of resources and technological innovation, but to increase their profits by overusing environmental resources that do not belong to them and transferring the costs that should be paid to others. However, this excessive use of environmental resources will inevitably lead to environmental pollution.

ISSN: 0010-8189

C CONVERTER 2020

www.converter-magazine.info 
3.1.3 Game Conclusion

From the analysis of the game of development and protection between tourism enterprises, it is easy to see that under the completely competitive market economy without government intervention and constraints, the game side is dominated by reason and tends not to cooperate to form a non-cooperative game. The Nash equilibrium of game is unfavorable or inefficient to environmental protection, which is the actual problem in tourism development and protection at present.

\subsection{Game of Protection and Supervision between Tourism Enterprises and Government}

In the tourism market without government intervention, enterprises adopt non-cooperative game on environmental protection, that is, the two sides do not tend to cooperate and protect the environment together. Therefore, the supply of public goods with strong positive and external benefits is inefficient. The market failure often becomes the reason for the government to intervene in the tourism market, and the tourism enterprises are supervised accordingly, thus the game of investment protection and supervision and management is formed between the enterprises and the government.

\subsubsection{Model assumptions}

Assuming that all the relevant tourism departments are regarded as an enterprise which constitutes with government a dynamic game. In the dynamic game between enterprise and government, if only the government participates, it does not play its mandatory and authoritative characteristics. Government failure will make this dynamic game infinite.

a. Players

a tourist area resource development enterprises and tourism area government departments.

b. Strategies

When the government makes regulations on the protection of tourism resources, tourism enterprises can choose to implement or not. If tourism enterprises do not implement protection regulations, the government can also choose to supervise or not. If the enterprise does not enforce the protection regulations again after the punishment of the government, the tourism government and the enterprise will continue to play the game, and the government will adopt a stronger strategy.

c. Payoff of players

Government income generally refers to the illegal development of enterprises to supervise the benefits obtained. The profit of enterprises includes: the profit brought by the implementation of the development and protection regulations formulated by government departments; those obtained by enterprises when they carry out illegal development, but the government does not intervene; and that of enterprises implementing illegal development while the government carries out rectification.

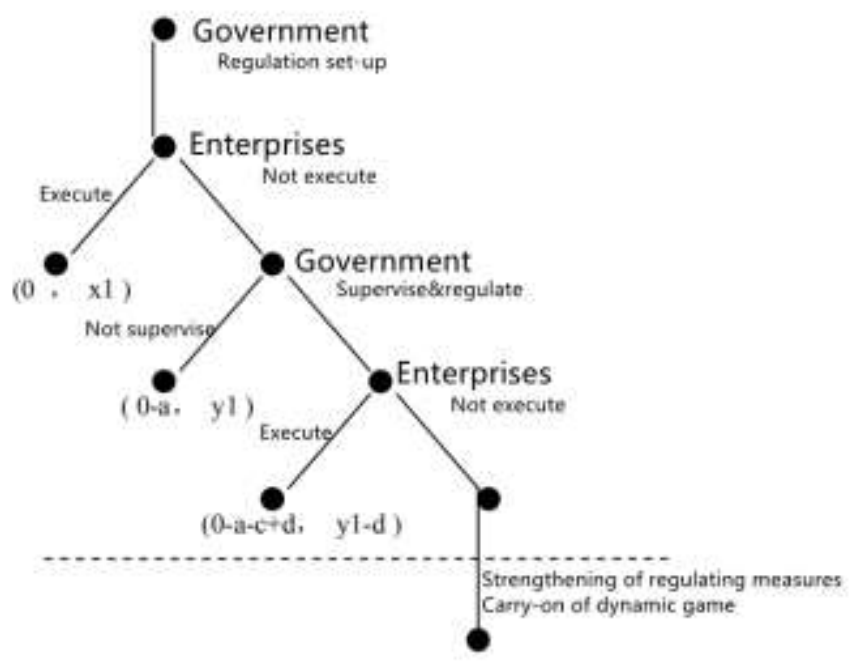

ISSN: 0010-8189

(C) CONVERTER 2020 


\section{Fig 3. The subgame between the Government and the tourism business}

\subsubsection{Model analysis (Fig 3)}

During the dynamic game between the government and the tourism enterprises, if the enterprises follow the environmental protection regulations formulated by the government at the beginning and fulfill the environmental protection obligations, the dynamic game will be terminated in advance. At this time, the profit obtained by the enterprises is $\mathrm{x} 1$. The government should bear the negative benefits (pollution control costs) due to environmental damage, that is, the government's profit is “- a", while the enterprise's income from non-investment protection is y1. Obviously, $\mathrm{y} 1>\mathrm{x} 1$ is the driving force for companies to choose not to implement protection regulations, because when investing in protection, the long-term features of environmental improvement often invest in environmental protection, that is, the $\mathrm{y} 1>\mathrm{x} 1$.

However, as a "visible hand" in the market, government intervention must supervise and rectify the illegal behavior of enterprises and promote the sustainable development of tourism in tourist destinations. Therefore, in general, the government will supervise the pollution of enterprises and take appropriate punishment. Suppose the cost of government supervision and regulation is "- c", and the penalty for the discovery and punishment of the enterprise's unprotected behavior is " $d$ ", then the income of the government and the enterprise is " $0-a-c+d, y 1-d$ ". At this time, the government has played the role of macro-control, established the environmental pollution punishment mechanism in time, and urged enterprises to take measures to protect the environment, then the dynamic game between enterprises and the government will stop. It should be pointed out that the efficiency and punishment of government supervision restrict the effect of government supervision and regulation. The effective implementation of government supervision and regulation must be based on the following conditions: $0-a-c+d>0$, that is $\mathrm{d}>\mathrm{a}+\mathrm{c}$, the fine of government supervision and rectification when tourism enterprises pollute the environment is greater than the sum of supervision expenses plus environmental control expenses. It can be seen that if the higher the efficiency of government supervision, the greater the penalty, and the greater the probability of enterprise investment protection will be.

\subsubsection{Game Conclusion}

It can be seen from the analysis of the game between enterprises that the Nash equilibrium of the game tends to be unfavorable or inefficient to environmental protection without the government's intervention and restraint in the completely competitive market economy. After analyzing the dynamic game model between government and enterprise, it is easy to see the important role of government in the process of tourism resource development and protection. In this game, the government takes effective measures to supervise and renovate the tourism enterprises that have not fulfilled their environmental protection obligations, which can promote the enterprises to control the environmental pollution and maintain and improve the tourism resources and environment. It can be said that the market is not omnipotent, environmental protection needs government intervention. In particular, the government can actively take measures to protect the environment through taxation, regulation, establishment of incentive mechanisms and promotion of institutional reform. After the enterprise invests to protect the environment, it will inevitably produce the environmental economic benefit. In this case, the government should reward, encourage enterprises to further invest to protect the environment, and then produce economic benefits, thus forming an interactive virtuous circle.

\section{Analysis Results and Discussions}

By analyzing the emergence of environmental problems in the development of rural tourism resources, combining the game analysis of environmental protection between tourism enterprises and the game analysis of environmental protection between government and tourism enterprises, this paper provides some strategies for the protection of tourism resources in order to promote the rational development of rural tourism resources and promote the sustainable development of rural tourism.

\subsection{Improve the legal system and management system of tourism environmental protection}

ISSN: 0010-8189

(C) CONVERTER 2020 
Compared with environmental protection in general, tourism environmental protection involves a wider range and its environmental impact factors are more complex. Because of the market economy factor, the tourism enterprise often takes the pollution environment as the price to pursue the maximum profit. However, it is difficult to control the pollution of the tourism environment by the constellation of environmental protection laws and regulations. Thus, the relevant legislative departments should formulate and promulgate the relevant laws and regulations, such as the Tourism Law and the Interim Provisions on the Protection of the Tourism Environment, as soon as possible, so as to complete and perfect the existing system so that there are laws to abide by. At the same time, it is necessary to protect and control tourism environmental pollution through law and law-abiding, to establish and perfect a better tourism environmental protection management organization and a perfect management system, to supervise the environmental problems arising from tourism enterprises in tourism development, and to abide by the law.

\subsection{Strengthening the Government's Supervision and Administration on the Protection of Tourism Environment}

From the above analysis of development and protection among rural tourism institutions, under the completely competitive market economy without government intervention and constraints, tourism enterprises tend not to cooperate and form a non-cooperative game. The Nash equilibrium of the game (not protected, not protected) is unfavorable to environmental protection. In view of the existing problems in tourism development and protection, the government should take appropriate measures to give full play to the role of macro-control. In particular, the work of environmental protection in tourism should talk more about "prevention ", less about" treatment ", highlight the management idea of "prevention is better than treatment, prevention is better than treatment ", make the environmental protection work of tourism enterprises run through all stages of tourism planning, development and consolidation, and carry out macro-management of environmental monitoring, environmental capacity and overloading of scenic spots during specific planning, so as to avoid the short-term behavior of enterprises emphasizing output value and neglecting environment in the development and development of tourism, and avoid the management means of" mending the sheep and sheep "in a firm way.

\subsection{Strengthen the government's environmental pollution punishment and management efficiency}

After analyzing the dynamic game model between government and enterprise, it is easy to see the important role of government in the process of tourism resource development and protection. In this game, the government takes effective measures to supervise and renovate tourism enterprises that have not fulfilled their obligations of environmental protection, which can promote enterprises to control environmental pollution and maintain and improve the environment of tourism resources. The punishment and management efficiency of government departments play an important role in regulating and controlling enterprises to invest and protect the environment, which is the key that government departments should pay full attention to in environmental protection law enforcement.

4.4 Raising environmental awareness and involving all sectors of society in management

As a systematic project, tourism environmental protection involves stakeholders such as tourism government departments, tourism enterprise management departments, local community residents and tourists, and requires the participation of all stakeholders. Therefore, it is necessary to raise the awareness of tourism environmental protection of the whole nation and even inbound tourists through the education of legal concept, comprehensive concept, and long-term concept. At the same time, rural tourism should grasp and fully respect the residents' understanding of the development of tourism, attract the local community residents to actively participate in the development and management of tourism, and make sure that rural tourism is carried out to integrate rural resources and drive the rural comprehensive development.

\section{Conclusions}

ISSN: 0010-8189

(C) CONVERTER 2020

www.converter-magazine.info 
As a scarce resource, environment also has the attribute of public goods. The application of game theory in rural tourism development is to quantify the results of decision-making behavior between tourism enterprises and governments in tourism development and express the relationship of mutual influence more intuitively. From the game analysis of this paper, it is easy to see that under the completely competitive market economy without government intervention and restriction, tourism enterprises are easy to form non-cooperative games, and the Nash equilibrium of the game is unfavorable or inefficient to environmental protection. Under the effective supervision of the government, the Nash equilibrium of the game is improved, and the game reaches the equilibrium conducive to environmental protection, thus realizing the sustainable utilization of environmental resources. Therefore, the government should take effective measures to supervise and renovate the tourism enterprises that have not fulfilled their environmental protection obligations, which can promote the enterprises to control the environmental pollution and maintain and improve the tourism resources and environment.

\section{References}

[1] Baird, D. G., Gertner, R. H., \& Picker, R. C. (1998). Game theory and the law. Harvard University Press.

[2] Butler, R. W. (1980). The concept of a tourist area cycle of evolution: implications for management of resources. Canadian Geographer/Le Géographe canadien, 24(1), 5-12.

[3] Buhalis, D. (2000). Marketing the competitive destination of the future. Tourism management, 21(1), 97-116.

[4] Butler, R. (Ed.). (2006). The tourism area life cycle (Vol. 1). Channel view publications.

[5] Feeny, D. Hanna, S. \& McEvoy, A. F. (1996). Questioning the assumptions of the" tragedy of the commons" model of fisheries. Land economics, 187-205.

[6] Forsyth, T. J. (1995). Tourism and agricultural development in Thailand. Annals of tourism research, 22(4), 877-900.

[7] Farina, A. (2008). Principles and methods in landscape ecology: towards a science of the landscape (Vol. 3). Springer Science \& Business Media.

[8] Gao, J., \& Wu, B. (2017). Revitalizing traditional villages through rural tourism: A case study of Yuanjia Village, Shaanxi Province, China. Tourism Management, 63, 223-233. doi:10.1016/j.tourman.2017.04.003

[9] Guaita Martínez, J. M., Martín Martín, J. M., Salinas Fernández, J. A., \& Mogorrón-Guerrero, H. (2019). An analysis of the stability of rural tourism as a desired condition for sustainable tourism. Journal of Business Research, 100, 165-174. doi:10.1016/j.jbusres.2019.03.033

[10] Inskeep, E. (1991). Tourism planning: An integrated and sustainable development approach. John Wiley \& Sons.

[11] Kozak, M. (2001). Comparative assessment of tourist satisfaction with destinations across two nationalities. Tourism management, 22(4), 391-401.

[12] Lane, B. (1994). What is rural tourism? Journal of Sustainable Tourism, 2(1-2), 7-21. doi:10.1080/09669589409510680

[13] Marcouiller, D. W. (2016). Toward Integrative Tourism Planning in Rural America. Journal of Planning Literature, 11(3), 337-357. doi:10.1177/088541229701100306

[14] Mihalič, T. (2000). Environmental management of a tourist destination: A factor of tourism competitiveness. Tourism management, 21(1), 65-78.

[15] Myerson, R. B. (2013). Game theory. Harvard university press.

[16] Miller, M. L., \& Gallucci, V. F. (2004). Quantitative Tourism and Fishery Management: Some Applications of the Logistic Model. Tourism in Marine Environments, 1.

[17] Ritchie, J. R. Crouch, G. I., \& Hudson, S. (2000). Assessing the role of consumers in the measurement of destination competitiveness and sustainabelity. Tourism Analysis, 5(2-3), 69-76.

[18] Slee, B., Farr, H., \& Snowdon, P. (1997). The economic impact of alternative types of rural tourism. Journal of agricultural economics, 48(1-3), 179-192.

[19] Tribe, J., Font, X., Griffiths, N., Vickery, R., \& Yale, K. (2000). Environmental management for rural tourism and recreation. Cassell plc.

ISSN: 0010-8189

(C) CONVERTER 2020 
[20] Urban, D. L. (2006). Landscape ecology. Encyclopedia of Environmetrics, 3.

[21] Uysal, M., Chen, J. S., \& Williams, D. R. (2000). Increasing state market share through a regional positioning. Tourism Management, 21(1), 89-96.

[22] Vail, D., \& Hultkrantz, L. (2000). Property rights and sustainable nature tourism: adaptation and mal-adaptation in Dalarna (Sweden) and Maine (USA). Ecological Economics, 35(2), 223-242.

[23] Von Neumann, J. (1944). Morgenstern, 0. Theory of games and economic behavior, 3.

[24] Williams, D. R. (2001). Sustainability and public access to nature: Contesting the right to roam. Journal of sustainable tourism, 9(5), 361-371.

[25] Yang, Z., Shi, H., Yang, D, Ren, X, \& Cai, Y. (2015). Analysis of core stakeholder behaviour in the tourism community using economic game theory. Tourism Economics, 21(6), 1169-1187.

[26] Zhang, H. Q., Heung, V. C., \& Yan, Y. Q. (2009). Play or not to play-An analysis of the mechanism of the zero-commission Chinese outbound tours through a game theory approach. Tourism Management, 30(3), 366-371. 